\title{
Long term prognosis after occlusion of middle cerebral artery
}

\author{
T SACQUEGNA，P DE CAROLIS, A ANDREOLI， R FERRARA，P LIMONI，C TESTA, \\ E LUGARESI
}

\begin{abstract}
Seventy patients who had developed occlusion of the middle cerebral artery confirmed by angiography between 1970 and 1980 were followed up after an average of six years. Fourteen patients had died in the acute stage of the initial stroke. In the remaining 56 patients actuarial analysis showed that the observed incidence of survival for five years was $81.8 \%$ compared with an incidence of $94 \cdot 1 \%$ in a matched normal population. Six patients sustained new strokes, four of which were ipsilateral to the middle cerebral artery occlusion. The observed cumulative incidence of subsequent strokes was $2 \%$ a year for the first five years of follow up. Twelve patients developed epileptic seizures.
\end{abstract}

\section{Introduction}

The natural history and long term outcome of occlusion of the middle cerebral artery have not been clearly defined. As extracranial bypass surgery in occlusion of the carotid or middle cerebral artery is currently being evaluated ${ }^{1}$ the long term prognosis in patients who sustain further strokes on the occluded side is of interest. We undertook the present study to evaluate the long term prognosis in patients with occlusion of the middle cerebral artery.

\section{Patients and methods}

We received 70 patients ( 46 men and 24 women) with occlusion of the middle cerebral artery or its branches who had undergone cerebral angiography in our departments between 1970 and 1980. At the time of angiography their mean (SD) age was $54 \cdot 8$ (13) years. Fifty six had occlusion of the main stem of the middle cerebral artery ( 32 on the left side, 24 on the right side), and 14 had occlusion of one or more of its major branches (eight on the left side, six on the right side). Five patients had plaque or stenosis in the ipsilateral cervical internal carotid artery.

Sixty seven patients had been admitted to hospital for stroke ipsilateral to the occlusion of the artery and three patients for transient ischaemic attacks. On admission three patients presented with atrial fibrillation (due to valvular heart disease in one and to myocardial infarction in one). Before admission 12 patients had experienced earlier transient ischaemic attacks. Angiography was performed, by injecting the brachial artery or via the transfemoral route, within 24 hours of stroke in 16 patients, within two weeks in 37, and after more than two weeks in 17 .

Fourteen of the 70 patients ( 10 with occlusion of the middle cerebral

Institute of Neurology, University of Bologna, Bologna, Italy

T SACQUEGNA, MD, physician

P DE CAROLIS, MD, physician

R FERRARA, MD, physician

E LUGARESI, MD, physician

First Division of Neurosurgery, Bellaria Hospital, Bologna

A ANDREOLI, MD, surgeon

P LIMONI, MD, surgeon

C TESTA, MD, surgeon

Correspondence to: Dr T Sacquegna, Clinica Neurologica, Università di Bologna, 40123 Bologna, Italy. artery and four with occlusion of its branches) died in the acute stage of the initial stroke. Follow up data on the occurrence of stroke, myocardial infarction, transient ischaemic attacks, epileptic seizures, and death were obtained in the remaining 56 patients either by personal examination or by direct telephone interview with the general practitioner. The net probability of death during follow up was determined by actuarial analysis ${ }^{2}$ and the cumulative risk of stroke by the Kaplan-Meier method. ${ }^{3}$

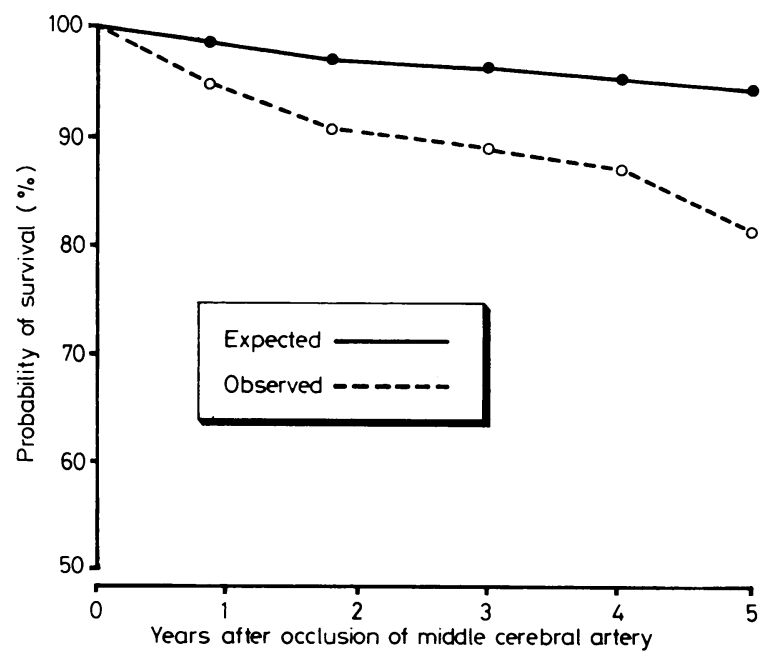

Observed survival after occlusion of middle cerebral artery in 56 patients. Expected survival is for a matched normal population.

\section{Results}

All 56 patients who survived the initial stroke were followed up. The period of follow up averaged six years, during which 14 patients died; the cause of death was stroke in three, cardiac disease in four, and cancer and miscellaneous disorders in seven. Actuarial analysis showed that the observed incidence of survival over five years was $81.8 \%$ compared with an incidence of $94.1 \%$ in a normal population of similar age and sex distribution (figure).

Six patients sustained a new stroke during the period of follow up. Stroke ipsilateral to the occlusion of the middle cerebral artery occurred in four patients, one of whom died, and contralateral stroke occurred in two, both of whom died. The observed cumulative incidence of stroke was $3.5 \%$ at one year, $5.5 \%$ at two years, $7.6 \%$ at three and four years, and $10.4 \%$ at five years. Of the 10 patients who had occlusion of the branches of the middle cerebral artery two died from lung disease and one suffered an ipsilateral stroke in the follow up period. Of five patients with a concomitant lesion of the ipsilateral carotid artery, one died from the first stroke and one died of a subsequent contralateral stroke. Five patients with occlusion of the middle cerebral artery were aged under 35 at the time of angiography. None of these had subsequent strokes.

Five patients had transient ischaemic attacks during the period of follow up (four ipsilateral to the artery occlusion, one in the vertebrobasilar area). Seven patients sustained myocardial infarction. Twelve of the 56 patients developed epileptic seizures (both partial motor and secondarily generalised seizures in eight, secondarily generalised partial seizures alone in four). (We considered only epilepsy occurring late after ischaemia-that is, at least one epileptic seizure occurring two weeks after stroke.) The epileptic seizures developed in most patients within two years after the stroke and were easily controlled with anticonvulsant drugs. 
None of the patients studied received treatment with anticoagulants, although a few received dipyridamole. Of the 42 patients still alive at the end of the follow up period, nine had returned to work, 16 required help, and 17 were totally disabled.

\section{Discussion}

Several studies have reported the typical clinical and angiographic features of middle cerebral artery occlusion-namely, that occlusion of this artery usually develops in young patients, commonly presents as a stroke, and is associated with lesions that are often not atherosclerotic. ${ }^{4-6}$ Knowledge of the natural long term prognosis associated with occlusion of the middle cerebral artery is, however, still largely incomplete.

Lascelles and Burrows reported that, of 59 patients with occlusion of the middle cerebral artery, 12 died from the first stroke; of the 47 survivors, three died of miscellaneous causes and one of fatal stroke. ${ }^{7}$ Kaste and Waltimo found that of 74 survivors of a first stroke due to occlusion of the middle cerebral artery, four had a second stroke, the locations of which were not given. ${ }^{8}$ Hinton et al reported on 16 patients with stenosis of the middle cerebral artery ${ }^{9}$ : during a follow up that lasted from one month to six years two patients developed an early stroke and one had repeated transient ischaemic attacks.

In our study only four patients had a new stroke on the occluded side during follow up, representing less than $2 \%$ a year for the first five years after angiography. The risk of subsequent strokes after occlusion of the middle cerebral artery is therefore quite small. Occlusion of the internal carotid artery has been reported by Furlan et al $(2 \% \text { a year })^{10}$ and by Norrving and Nilsson $(1 \% \text { a year })^{11}$ to have a similarly good prognosis. Two recent studies, however, reported that intracranial stenosis of the internal carotid artery is associated with a high risk of subsequent strokes. ${ }^{12} 13$
In our study we found a high incidence of late epileptic seizures. This was probably because occlusion of the middle cerebral artery is often due to embolism and infarcts are cortical.

We thank Dr M Marinelli for statistical help.

\section{References}

1 Barnett HJM, Peerless SJ, McCormick CW. In answer to the question: "As compared to what ?" A progress report on the EC/IC bypass study. Stroke 1980;11:137-40.

${ }^{2}$ Elveback L. Estimation of survivorship in chronic disease: the "actuarial" method. Fournal of the American Statistical Association 1958;53:420-40.

${ }^{3}$ Kaplan EL, Meier P. Nonparametric estimation from incomplete observations. Fournal of the American Statistical Association 1958;53: 457-81.

4 Silverstein A, Hollin S. Internal carotid vs middle cerebral artery occlusions. Arch Neurol 1965;12:468-71.

${ }^{5}$ Sindermann F, Bechinger D, Dichgans J. Occlusions of the internal carotid artery compared with those of the middle cerebral artery. Brain 1970;93:199-210.

${ }^{6}$ Lhermitte F, Gautier JC, Derouesné C. Nature of occlusions of the middle cerebral artery. Neurology 1970;20:82-8.

7 Lascelles RG, Burrows EH. Occlusion of the middle cerebral artery. Brain $1965 ; 88: 85-96$.

${ }^{8}$ Kaste M, Waltimo O. Prognosis of patients with middle cerebral artery occlusion. Stroke 1976;7:482-5.

${ }^{9}$ Hinton RC, Mhr JP, Ackerman RH, Adair LB, Fisher CM. Symptomatic middle cerebral artery stenosis. Ann Neurol 1979;5:152-7.

10 Furlan AJ, Whisnant JP, Baker HL Jr. Long-term prognosis after carotid artery occlusion. Neurology 1980;30:986-8.

11 Norrving B, Nilsson B. Carotid artery occlusion: acute symptoms and long term prognosis. Neurol Res $1981 ; 3: 125-8$.

12 Marzewski DJ, Furlan AJ, Louis P St, Little JR, Modic MT, Williams G. Intracranial internal carotid artery stenosis: longterm prognosis. Stroke $1982 ; 13: 821-4$.

${ }^{13}$ Craig DR, Meguro K, Watridge C, Robertson JT, Barnett HJM, Fox AJ. Intracranial internal carotid artery stenosis. Stroke 1982;13:825-8.

(Accepted 16 February 1984)

\title{
Respiratory viruses and sudden infant death
}

\author{
ALAN L WILLIAMS, ERIC C UREN, LESLEY BRETHERTON
}

\begin{abstract}
Viruses were shown to be present in the respiratory tract in 200 of 763 cases of the sudden infant death syndrome studied in the nine years 1974-82. Epidemiological and pathological evidence suggested that the distribution of viruses in the sudden infant death syndrome differs between infants aged 3 months or less and those aged over 3 months: the incidence of detection of virus was $14 \%$ in the younger group compared with $39 \%$ in the older group. The distribution of the viruses in these two groups was compared with that in 1341 live infants with respira-
\end{abstract}

Royal Children's Hospital, Melbourne, Australia

ALAN L WILLIAMS, MD, FRCPA, director, department of pathology, and paediatric pathologist for coroner, city of Melbourne ERIC C UREN, BSC, virologist

LESLEY BRETHERTON, BSC, technical assistant

Correspondence and requests for reprints to: Dr Alan L Williams. tory virus infections. Adenovirus, influenza virus, parainfluenza virus, and rhinovirus had similar distribution among the victims of the sudden infant death syndrome and live controls. The incidence of detection of respiratory syncytial virus was increased in the older infants dying of the sudden infant death syndrome (90\% of the cases detected) compared with the older group of live infants $(53 \%)$.

Antibody studies, detection of virus, and epidemiological data suggest that respiratory syncytial virus may be a precipitating factor of sudden death in older infants.

\section{Introduction}

During the past 20 years many workers have reported the isolation of viruses from infants who have died suddenly and unexpectedly and for whose death no adequate explanation can be given. ${ }^{1-5}$ Such viruses have been isolated most commonly from faeces or secretions of the respiratory tract. We report the detection of virus by isolation or immunofluorescence, or both, in secretions of the respiratory tract from a series of 763 infants dying suddenly and unexpectedly and from controls. 